\title{
Review on Food Animals Stress and Food Quality and Safety Risk
}

\author{
Zerihune Teshome ${ }^{1 *} \quad$ Misrak Abraham $^{1} \quad$ Wendwesen Teka $^{2}$ \\ 1.Wolaita Zone Livestock and Fishery Resources Department, Wolaita Sodo SNNPR, Ethiopia \\ 2.Wolaita Sodo Agricultural TVET College, Wolaita Sodo, SNNPR, Ethiopia
}

\begin{abstract}
SUMMERY
All food animals will experience some level of stress during their lives. Stress reduces the fitness of an animal, which can be expressed through failure to achieve production performance standards or targets, or more drastically, through injury, disease and death. Stress in food animals can also have detrimental effects on the quality and safety of food products. However, knowledge of food animals' stress and its effect on the quality and safety of food products is scanty. The aim of this review article is to examine the current knowledge on the potential effects of stress in food animals on food quality and safety risk. Stress in food animals can have detrimental effects on the quality of food products. The effect includes; decline in processing properties, functional quality, eating quality and shelf life. Therefore, it is very automatic to cause huge financial loss to the food industry. Furthermore, stress in food animals have a significant deleterious effect on food safety through different potential mechanisms affecting the susceptibility of food animals to infections as well as the carriage and shedding of foodborne pathogens such as E. coli O157:H7, Salmonella, and Campylobacter. Since stress in life is unavoidable, we can never expect to develop ideal conditions that will always keep our animals stress free. Therefore, changes in management practices to promote animal well-being and to minimize stress can reduce losses in product yield and quality, as well as food safety risks to consumers.
\end{abstract}

Keywords: Food animals; food quality; food safety; stress

DOI: $10.7176 / \mathrm{JBAH} / 12-1-02$

Publication date: January $31^{\text {st }} 2022$

\section{INTRODUCTION}

Meeting consumer concerns about food quality and safety have been identified as key points for future livestock production. In particular, food safety (freeness from hazard) has emerged as an absolute but minimum requirement for the future success of livestock and food production. There are pathogens in food of animal origin that have long been traced to food animals and can cause human illness (Julie, 2010).

All food animals experience some level of stress during their lives. Stress reduces the fitness of an animal, which can be simply expressed through failure to achieve production performance standards or targets (Mitlohner et al., 2001; Collier et al., 2006; Estevez, 2007; White et al., 2008), or more drastically, through disease and death (Vecerek et al., 2006; Duff and Galyean, 2007; Fitzgerald et al., 2009).

It has been demonstrated that stress in food animals can also have detrimental effects on the quality of food products (meat, milk and egg) (Ferguson and Warner, 2008; Giustini et al., 2007; Reynard and Savory, 1999). In addition, there is increasing evidence showing that stress can have a significant deleterious effect on food safety through a variety of potential mechanisms (Rostango, 2009). The magnitude of any negative effect is generally thought to be a function of the type, duration and intensity of the individual stressors and the susceptibility of the animal to them (Ferguson et al., 2001).

Therefore, this review article was prepared with the objective of compiling the current knowledge and evidence available in the scientific literature examining what is known about the relationship between stress in food animals and food quality and safety risk.

\section{OVERVIEW OF ANIMALS STRESS}

\subsection{What is Stress and Stressor?}

Stress, a response to adverse stimuli, is a difficult concept to define because of its fundamental abstract and volatile interpretation. According to Selye (1976), stress is "the nonspecific response of the body to any demand," and stressor is "an agent that produces stress at any time." In other words, stress represents the reaction of the body (i.e., a biological response) to stimuli that disturb its normal physiological equilibrium or homeostasis, whereas stressors can be defined as conditions that endanger, or are perceived to endanger, the homeostasis of an individual and, therefore, cause a stress response or reaction. Whether a stressor can be considered harmful depends on how an organism is able to cope with a threatening situation as it maintains a state of homeostasis (Van de Kar and Blair, 1999).

\subsubsection{Stresses as a Physiological Mechanism}

The discoveries of metabolic, immunological and neuroendocrine mechanisms make it possible to describe the stress reaction in physiological terms (Balm, 1999). A multitude of hormones (e.g., adrenocorticotropic hormone (ACTH), glucocorticoids, and catecholamines) are involved in the stress response (Matteri et al., 2000). The 
adrenal glands have a key role in hormonal reactions to stress as they are involved both in the hypothalamicpituitary-adrenocortical (HPA) axis and the symphatho-adreno-medullary system (Moberg, 2000). Adverse situations trigger responses of the adrenals, which result in an increase in glucocorticoid (i.e., cortisol) and/or catecholamine (i.e., epinephrine and norepinephrine) secretion. These increases are the front-line endocrine mechanisms to defend the organism against the stressful conditions.

As a physiological mechanism, stress per se is not inherently bad (Moberg, 2000). For example, glucocorticoids are released in response to situations that are not normally regarded as stressful, including courtship, copulation and hunting (Broom and Johnson, 1993). In addition hormones, which increase during stress periods, are also part of the hormonal cascade causing parturition in some species (McLean and Smith, 2001). During short-term stress, glucocorticoids improve fitness by energy mobilization and may change behavior (Korte et al., 1993). However, severe chronic stress (prolonged periods of high cortisol concentrations) may decrease individual fitness by immunosuppression and atrophy of tissues. In addition, the reproductive success of the animal is decreased (Liptrap, 1993; Dobson, 1995).

\subsection{Measurement of Animals Stress}

A major problem of applied stress research is to determine how to measure stress in animals. Many researchers relied on a variety of endocrine, behavioural, autonomic nervous system and immunological end-points to measure stress. Unfortunately, none of these measures has proved to be a litmus test for stress (Moberg, 1985).

Cortisol concentrations in blood are used widely to study HPA activity. This presents some problems related to the invasiveness of blood sampling techniques (Stewart et al., 2005) and alternatives have been used (e.g., urine, saliva, faeces, milk). In addition, the cortisol response to a noxious stimulus may not persist for the duration of the effects of the stressor and thus may not reflect the overall impact of the stressor on the animal. There is also little evidence that cortisol concentrations vary with the severity of the stressor, as the HPA axis is highly sensitive to a range of stimuli that may not be harmful to the animal (Mormede et al., 2007).

Physiological changes elicited by the sympathetic nervous system (SNS) (e.g., increased heart rate and plasma catecholamines) may be more useful than cortisol for assessing acute responses to stress because of their quicker response time. However, relatively few studies have measured Sympathoadrenal (SA) responses, such as plasma catecholamines, in farm animals. This may be due to the high cost of assays and practical difficulties in collection and measurement of catecholamines, as a result of their low concentrations and short half-life (1-2 minute) in plasma (Hjemdahl, 1993).

Behavioural responses to a noxious experience have an advantage in that they occur immediately, provide a good indication of the duration and different phases of a painful experience (Mellor et al., 2000) and can be measured non-invasively. However, the measurement and interpretation of behavioural responses can be difficult and the variation in responses can be misleading (Rushen, 2000). Responses may vary depending on the individual's characteristics, previous experience, breed and species.

\subsection{Stress in Food Animals}

Naturally, food animals will be challenged by different stressors and, consequently, develop varying degrees of stress responses during their lives. Each environment poses its unique set of stressors to which the animal must be able to appropriately respond (Siegel, 1995). Modern animal production systems typically house animals in large and homogeneous groups, in enclosed environments (e.g., barns, rooms, and pens). Often, these production systems place the animals into situations in which it must be able to adapt and respond to a variety of stressors, which are usually confounded with one another (i.e., occurring simultaneously or overlapping). Some of the common factors that produce stress when they act excessively within any animal production system include inadequate nutrition, deprivation of water and/or feed, heat, cold, overcrowding, and handling (i.e., interaction with humans, or human manipulation of the animals) (Rostango, 2009). Additionally, most food animals are transported at some stage in their lives, sometimes to places where feed ingredients are more readily available, to a different owner or a different raising location, and sometimes to slaughter. The handling, loading, transporting, and unloading of animals can have substantial detrimental effects on their well-being by causing stress. Moreover, during this process, animals can be exposed to a range of challenging stimuli, including handling and increased human contact, transport (vibration, movement, and jolting), novel/unfamiliar environments, food and water deprivation, changes in social structure (through separation and mixing during transport and/or at the final destination), and changes in climatic conditions (i.e., heat and cold). These challenges perturb the homeostasis of the animals, and an adaptive response is activated in an attempt to restore balance (Rostango, 2010).

\section{EFFECTS OF STRESS ON FOOD QUALITY}

Food quality (i.e., a total of traits and criteria, which characterize food as regards its nutritional value, sensory value, convenience as well as safety for a consumer's health) is directly related to the treatment animals receive; minimizing food animals' stress can enhance it (Daniel et al., 2011). 


\subsection{Meat Quality}

The energy required for muscle activity in the live animal is obtained from sugars (glycogen) in the muscle. In the healthy and well-rested animal, the glycogen content of the muscle is high (Warriss, 2000). After the animal has been slaughtered, the glycogen in the muscle is converted into lactic acid, and the muscle and carcass becomes firm (rigor mortis). This lactic acid is necessary to produce meat, which is tasteful and tender, of good keeping quality and good colour. If the animal is stressed before and during slaughter, the glycogen is used up, and the lactic acid level that develops in the meat after slaughter is reduced. This will have serious adverse effects on meat quality (FAO, 2001).

\section{A. Pale Soft Exudative (PSE) Meat}

PSE in pigs is caused by severe, short-term stress just prior to slaughter, for example during off-loading, handling, holding in pens and stunning (Rosenvold and Andersen, 2003). Here the animal is subjected to severe anxiety and fright caused by manhandling, fighting in the pens and bad stunning techniques. All this may result in biochemical processes in the muscle in particular in rapid breakdown of muscle glycogen and the meat becoming very pale (Figure 1A) with pronounced acidity ( $\mathrm{pH}$ values of 5.4-5.6 immediately after slaughter) and poor flavor (Adzitey and Nurul, 2010). This type of meat is difficult to use or cannot be used at all by butchers or meat processors and is wasted in extreme cases. Allowing pigs to rest for one hour prior to slaughter and quiet handling will considerably reduce the risk of PSE (FAO, 2001).

\section{B. Dark Firm and Dry (DFD) Meat}

This condition can be found in carcasses of cattle or sheep and sometimes pigs and turkeys soon after slaughter. The carcass meat is darker and drier than normal and has a much firmer texture (Figure 1C) (Mark, 2007). The muscle glycogen has been used up during the period of handling, transport and pre-slaughter and as a result, after slaughter, there is little lactic acid production, which results in DFD meat. This meat is of inferior quality as the less pronounced taste and the dark colour is less acceptable to the consumer and has a shorter shelf life due to the abnormally high $\mathrm{pH}$ value of the meat (6.4-6.8) (Adzitey and Nurul, 2010). DFD meat means that the carcass was from an animal that was stressed, injured or diseased before being slaughtered (FAO, 2001).

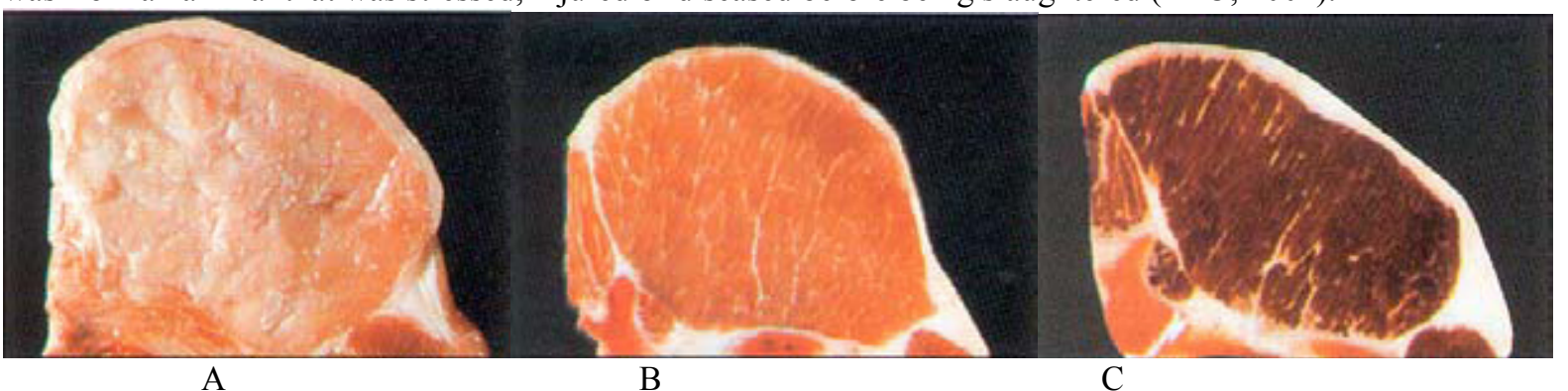

Figure 1: Typical figure of pale soft and exudative (A), normal (B) and dark firm and dry (C) meat.

\section{Spoilage of Meat}

It is necessary for animals to be stress and injury free during operations prior to slaughter, so as not to unnecessarily deplete muscle glycogen reserves. It is also important for animals to be well rested during the 24 hour period before slaughter. This is in order to allow muscle glycogen to be replaced by the body as much as possible (FAO, 2001). It is important that the glycogen levels in the muscles of the slaughtered carcass are as high as possible, to develop the maximum level of lactic acid in the meat. This acid gives meat an ideal $\mathrm{pH}$ level, measured after 24 hours after slaughter, of 6.2 or lower. The 24 hour (or ultimate) $\mathrm{pH}$ higher than 6.2 indicates that the animal was stressed, injured or diseased prior to slaughter. Lactic acid in the muscle has the effect of retarding the growth of bacteria that have contaminated the carcass during slaughter and dressing. These contaminating bacteria cause spoilage of the meat during storage, particularly in warmer environments, and the meat develops off-smells, colour changes, rancidity and slime (Warriss, 2000). This is spoilage, and these processes decrease the shelf life of meat, thus causing wastage of valuable food. Thus, meat from animals, which have suffered from stress or injuries during handling, transport and slaughter, is likely to have a shorter shelf life due to spoilage. This is perhaps the biggest cause for meat wastage during the production processes (Ferguson, 2003).

\section{Bruising}

Bruising is the escape of blood from damaged blood vessels into the surrounding muscle tissue. This is caused by many stressful conditions like physical blow by a stick or stone, animal horn, metal projection or animal fall and can happen anytime during handling, transport, penning or stunning. Bruises can vary in size from mild (approximately $10 \mathrm{~cm}$ diameter) and superficial, to large and severe involving whole limbs, carcass portions or even whole carcasses. Bruising of muscle tissue affects the quality of meat because the $\mathrm{pH}$ levels increase around the bruising, so it decomposes and spoils rapidly (Gregory, 2003). 


\subsection{Milk Quality}

Dairy animals are very sensitive to rough handling and climatic variations that greatly influence their welfare and their ability to produce milk. Heat stress (HS) conditions are normally associated with a decline of the production performances as they determine the activation of thermoregulation mechanisms in order to avoid hyperthermia and maintain the vital functions of the animals (Nardone et al., 2006). The exposure to HS is also able to strongly modify ruminant milk gross composition. Milk protein levels have generally been shown to decrease under HS (Giustini et al., 2007; Kamiya et al., 2005; Bouraoui et al., 2002). Results on milk fat levels differ among reports; however, many researchers (Giustini et al., 2007; Bouraoui et al., 2002) have showed declines of this parameter. Only a limited number of studies have focused on the effect of HS on ruminant milk fatty acid (FA) profile and the results obtained by different authors are sometimes conflicting (Lacetera et al., 2003).

\subsection{Egg Quality}

A range of types of general stress can affect eggshell quality. High population density was shown some times ago to increase the production of body-checked eggs (Ravindran et al., 1999). Body-checked eggs are thought to result from contraction of the shell gland while the egg shell is in the early stage of formation. Stress can also induce delays in the timing of oviposition when hens retain their egg and this can result in an increase incidence of white-band and slab-sided eggs (Suksupath et al., 1999). The white-banded egg is the one that is retained beyond the normal oviposition time while the slab-sided egg is the one that entered the shell gland while the first egg was still there. The stressor of relocation, or exclusion from next boxes of birds that normally had access to them, can cause an increase in incidence of calcium "dusted", white-banded, slab-sided and misshapen eggs (Suksupath et al., 1999). Even handling of birds which are not used to handling can increase the incidence of cracked egg. Many of the deleterious effect of general stress on egg quality can be induced by injections of adrenaline (Reynard and Savory, 1999).

\section{EFFECTS OF STRESS ON FOOD SAFETY}

The gastrointestinal tract is the primary habitat of a variety of bacteria, including foodborne pathogens. Colonization of food animals by pathogens such as E. coli O157:H7, Salmonella, and Campylobacter, and their subsequent distribution along the human food chain are a major public health and economic concern for the food industries (Rostango, 2009).

\subsection{Indirect Effects}

The enteric nervous system (ENS) is an integrative network located within the wall of the gastrointestinal tract that controls the microcirculation, motility, and exocrine and endocrine secretions of the gastrointestinal tract. It is bidirectionally linked to the central nervous system (CNS) by the sympathetic and the parasympathetic pathways forming the brain-gut axis (Goyal and Hirano, 1996; Costa et al., 2000). Although some researchers are only beginning to understand the complex physiology of brain-gut interactions involved in stress-related gastrointestinal alterations, there is evidence that stress may not only be responsible for functional disorders, but may also contribute to inflammatory disorders and infections of the gastrointestinal tract (Soderholm and Perdue, 2001; Bhatia and Tandon, 2005). Additionally, continually high level of stress hormones as a result of chronic stress has a well-documented link to suppression of the immune system leading to increased susceptibility to infectious disease (Glaser and Kiecolt, 2005).

From many years of research on the potential effects of stress on the gastrointestinal tract of laboratory animals, it is known that during stress, the release of catecholamines results in a decreased gastric acid production, delayed gastric emptying, and accelerated intestinal motility and colonic transit (Tache et al., 1999; Monnikes et al., 2001). Consequently, the increase of the $\mathrm{pH}$ in the stomach leads to a greater probability that foodborne pathogens (such as Escherichia coli, Salmonella, and Campylobacter) will survive gastric passage and colonize the gastrointestinal tract. Additionally, hormones released in response to stress also act at the intestinal mucosa to alter interactions between luminal microorganisms and epithelial cells (Wang and $\mathrm{Wu}, 2005$ ). For instance, Saunders et al. (2002) observed increased permeability of the intestinal mucosa in rats subjected to psychological and physical stress. This functional change in the intestinal mucosa permeability leads to increased microbial invasion ability in the gastrointestinal tract (i.e., increased translocation rate). Consequently, animals under stress become more susceptible to new (and more severe) infections, and may carry more pathogens in the gastrointestinal tract and associated lymphoid tissue. Moreover, animals that already excrete bacteria can shed more with an increased defecation frequency, because of increased intestinal motility (Barone et al., 1990).

The gastrointestinal tract is an environment in which, normally, there is a significant presence of catecholamines (particularly, norepinephrine). Further, during episodes of stress, catecholamines are released by the ENS, or spill over from the systemic circulation (Aneman et al., 1996; Eisenhofer et al., 1997), causing significant local increases. These changes can then markedly affect the status and behavior of the resident 
microbiota and colonizing pathogens, as discussed above (i.e., indirectly, through suppression of the immune system, and promoting physiological alterations in the gastrointestinal tract).

\subsection{Direct Effects}

Until recently, the concept of how stress in animals influences the outcome of infections was primarily based on the immune response, and on other potential indirect effects, as discussed above (i.e., physiological changes in the gastrointestinal tract). However, a few years ago, the first studies were conducted to examine the direct influence of stress-related neuroendocrine hormones, such as the catecholamines, on bacterial growth (Lyte and Ernst, 1992). The idea that bacteria could directly respond to the neuroendocrine outflow that resulted from the stress response has led to a series of studies that demonstrated significant increase in growth of gramnegative bacteria exposed to norepinephrine in vitro (Lyte and Ernst, 1993; Lyte et al., 1996). Additionally, virulenceassociated factors, such as adhesions in enterotoxigenic E. coli and toxins in enterohemorrhagic E. coli (Lyte et al., 1996, 1997), were shown to increase in norepinephrine-stimulated bacteria. Such direct effects of catecholamines on the bacteria provided evidence of a new pathway for host stress-induced alterations of infections (Lyte, 1993).

\section{CONCLUSION AND RECOMMENDATION}

Most food animals are exposed to stressful conditions in the farm, during transportation, at the market and in the Lairage and processing plant. Stress reduces the fitness of an animal, which can be expressed through failure to achieve production performance standards, or through disease and death. Stressful handling is also a compromise of animal's welfare. As briefly discussed in this review article, there are increasing evidence that illustrate how stress has significant deleterious effect on food quality and safety. Moreover, those potential mechanisms are identified and researched, though it is an on-going process. Since stresses have considerable effects on the general economy and on the public health, it should not be overlooked and changes in management practices is important to promote animal well-being and to minimize stress, and therefore reduce losses in product yield and quality, as well as food safety risks to consumers.

\section{REFERENCES}

Adzitey F and Nurul H (2010). Pale Soft Exudative (PSE) and Dark Firm Dry (DFD) Meats: Causes and measures to reduce these incidences. International Food Research Journal (accepted).

Aneman A, Eisenhofer G, Olbe L, et al. (1996). Sympathetic discharge to mesenteric organs and the liver. Evidence for substantial mesenteric organ norepinephrine spillover. J Clin Invest 97: 1640-1646.

Balm PHM, Preface (1999). In: Balm PHM, editor. Stress physiology in animals. Sheffield Academic Press.

Barone FC, Deegan JF, Price WJ, et al. (1990). Cold-restraint stress increases rat fecal pellet output and colonic transit. Am J Physiol 258: G329-G337.

Bouraoui R, Lahmar M, Majdoub A, Djemali M and R Belyea (2002). The relationship of temperature humidity index with milk production of dairy cows in a Mediterranean climate. Animal Research 51(6): 479-491.

Broom DM, Johnson KG (1993). Stress and animal welfare. London: Chapman \& Hall.

Collier RJ, Dahl GE, and VanBaale, MJ (2006). Major advances associated with environmental effects on dairy cattle. J Dairy Sci 89: 1244-1253.

Costa M, Brookes SJH and Hennig GW (2000). Anatomy and physiology of the enteric nervous system. Gut 47 : iv15-iv19.

Daniel MR, Hector OG, Miguel G, Patricia R, Roberto M, Monica SH and Maria E (2011). Therapeutic Approaches in Animals to Reduce the Impact of Stress During Transport to the Slaughterhouse: A Review. International Journal of Pharmacology 7: 568-578.

Dobson H, Smith RF (1995). Stress and reproduction in farm animals. J Reprod Fertil Suppl 49: 451-61.

Duff GC and Galyean ML (2007). Board-invited review: recent advances in management of highly stressed, newly received feedlot cattle. J Anim Sci 85: 823-840.

Eisenhofer G, Aneman A, Friberg P, et al. (1997). Substantial production of dopamine in the human gastrointestinal tract. J Clin Endocrinol Metab 82: 3864-3871.

Estevez I (2007). Density allowances for broilers: where to set the limits? Poult Sci 86: 1265-1272.

Ferguson DM (2003). Regulation of post-mortem glycolysis in ruminant muscle. PhD Thesis. University of New England, Armidale, Australia.

Ferguson DM and Warner RD (2008). Have we underestimated the impact of pre-slaughter stress on meat quality in ruminants? Meat Sci 80: 12-19.

Ferguson DM, Bruce HL, Thompson JM, Egan AF, Perry D, and Shorthose WR (2001). Factors affecting beef palatability - Farmgate to chilled carcass. Australian Journal of Experimental Agriculture 41: 879-891.

Fitzgerald RF, Stalder KJ, Matthews J.O, et al. (2009). Factors associated with fatigued, injured, and dead pig frequency during transport and lairage at a commercial abattoir. J Anim Sci 87: 1156-1166. 
Giustini L, Acciaioli A, Pianaccioli L, Surace R and O Franci (2007). Thermic stress effect on the main qualitative parameters of milk produced in the Mugello. Scienza e Tecnica Lattiero Casearia 58 (6): 383 402.

Glaser R, Kiecolt-Glaser JK (2005). Stress-induced immune dysfunction: implications for health. Nature Reviews Immunology 5: 243-251.

Goyal, RK and Hirano I (1996). The enteric nervous system. N Engl J Med 334: 1106-1115.

Gregory, NG (2003). Animal welfare and meat science. USA: CABI Publishing (pp. 64-92).

Hjemdahl, P (1993). Plasma catecholamines-analytical challenges and physiological limitations. Baillieres Clin. Endocrinol. Metab. 7: 307-353.

Julie M (2010). Swine Stress and Pathogen Shedding. Originally published as a National Pork Board Factsheet.

Kamiya M, Iwama Y, Tanaka M and S Shioya (2005). Effects of high ambient temperature and restricted feed intake on nitrogen utilization for milk production in lactating Holstein cows. Animal Science Journal 76(3): 217-223

Korte SM, Bouws GAH, Bohus B (1993). Central actions of corticotropin-releasing hormone (CR-H) on behavioral, neuroendocrine and cardiovascular regulation: Brain Corticoid Receptor Involvement. Horm Behav 27: 167-83.

Lacetera N, Bernabucci U, Ronchi B and A Nardone (2003). Physiological and productive consequences of heat stress. The case of dairy ruminants. In: Lacetera, Bernabucci, Khalifa, Ronchi, Nardone (eds.) Interactions between climate and animal production. European Association Animal Production Technical Series 7: 4559.

Liptrap RM (1993). Stress and reproduction in domestic animals. Ann NY Acad Sci 697: 275-84.

Lyte M (1993). The role of microbial endocrinology in infectious disease. J Endocrinol 137: 343-345.

Lyte M and Ernest S (1993). Alpha and beta-adrenergic receptor involvement in catecholamine-induced growth of Gram negative bacteria. Biochem Biophys Res Commun 190: 447-452.

Lyte M and Ernst S (1992). Catecholamine induced growth of Gram-negative bacteria. Life Sci 50: $203-212$.

Lyte M, Arulanandam BP and Frank CD (1996). Production of shigalike toxins by Escherichia coli O157:H7 can be influenced by the neuroendocrine hormone norepinephrine. J Lab Clin Med 128: 392-398.

Lyte M, Arulanandam BP, Nguyen K, et al. (1997). Norepinephrine induced growth and expression of virulence associated factors in enterotoxigenic and enterohemorrhagic strains of Escherichia coli. Adv Exp Med Biol 412: 331-339.

Mark (2007). Dark, Firm and Dry Beef. Beef facts, Texas Tech University.

Matteri RL, Carroll JA, Dyer CJ (2000). Neuroendocrine responses to stress. In: Moberg GP, Mench JA, editors. The biology of animal stress. CABI Publishing, p. 43-76.

McLean M and Smith R (2001). Corticotrophin-releasing hormone and human parturition. Reproduction 121: 493-501.

Mellor DJ, Cook CJ, Stafford KJ (2000). Quantifying some responses to pain as a stressor. In: Moberg GP, Mench JA (Eds.), The biology of animal stress: basic principles and implications for animal welfare, CABI Publishing, Wallingford, UK, pp. 171-198.

Mitlohner FM, Morrow JL, Dailey JW, et al. (2001). Shade and water misting effects on behavior, physiology, performance, and carcass traits of heat-stressed feedlot cattle. J Anim Sci 79: 2327-2335.

Moberg GP (1985). Biological response to stress: key to assessment of animal well-being? In: Moberg, G.P. (ed.) Animal Stress. American Physiological Society, Bethesda, Maryland, pp. 27-49.

Moberg GP (2000). Biological response to stress: implications for animal welfare. In: Moberg GP, Mench JA, editors. The biology of animal stress. CABI Publishing, p. 123-46.

Monnikes H, Tebbe JJ, Hildebrandt M, et al. (2001). Role of stress in functional gastrointestinal disorders. Evidence for stress induced alterations in gastrointestinal motility and sensitivity. Dig Dis 19: 201-211.

Mormede P, Andanson S, Auperin B, Beerda B, Guemene D, Malmkvist J, Manteca X, Manteuffel G, Prunet P, Van Reenen CG, Richard S, Veissier I (2007). Exploration of the hypothalamic-pituitary-adrenal function as a tool to evaluate animal welfare. Physiol. Behav. 92: 317-339.

Nardone A, Ronchi B, Lacetera N and U Bernabucci (2006). Climatic effects on productive traits in livestock. Veterinary Research Communications 30(1): 75-81.

Ravindran V, PH Selle and WL Bryden (1999). Effects of phytase supplementation, individually and in combination, with glycanase, on the nutritive value of wheat and barley. Poultry Sci 78: 1588-1599.

Reynard M and CI Savory (1999). Stress-induced oviposition delays in laying hens: duration consequences for eggshell quality, British Poultry Sci 40: 585-591.

Rosenvold, K. and Andersen, H.J. (2003): Factors of significance for pork quality - a review. Meat Sci 64: 219237.

Rostagno MH (2009). Can stress in farm animals increase food safety risk? Foodborne Pathogens and Disease 6 : $767-776$. 
Rostagno MH (2010). Stress in farm animals and food safety: Is there a connection? Food safety fact sheet. USDA-ARS-MWA, Livestock behavior research unit.

Rushen J (2000). Some issues in the interpretation of behavioural responses to stress. In: Moberg GP, Mench JA (Eds.), The biology of animal stress: basic principles and implications for animal welfare, CABI Publishing, Wallingford, UK, pp. 23-42.

Saunders PR, Santos J, Hanssen NPM, et al. (2002). Physical and psychological stress in rats enhances colonic epithelial permeability via peripheral CRH. Dig Dis Sci 47: 208-215.

Selye H (1976). Forty years of stress research: principal remaining problems and misconceptions. Can Med Assoc J 115: 53-56.

Siegel HS (1995). Gordon Memorial Lecture. Stress, strains and resistance. Br Poult Sci 36: 3-22.

Soderholm JD and Perdue MH (2001). Stress and the gastrointestinal tract. II. Stress and intestinal barrier function. Am J Physiol Gastrointest Liver Physiol 280: G7-G13.

Stewart M, Webster JR, Schaefer AL, Cook NJ, Scott SL (2005). Infrared thermography as a non-invasive tool to study animal welfare. Anim. Welf. 14: 319-325.

Suksupath S, EA Cole, RJ Cole and WL Bryden (1999). Toxicity of cyclopiazonic acid in the laying hen. Proceeding of the Australian Poultry Science Symposium, Sydney, pp: 94.

Tache Y, Martinez V, Million M, et al. (1999). Corticotropin-releasing factor and the brain-gut motor response to stress. Can J Gastroenterol 13(A): 18A-25A.

Van de Kar LD and Blair ML (1999). Forebrain pathways mediating stress-induced hormone secretion. Front Neuroendocrinol 20: 1-48.

Vecerek V, Grbalova S, Voslarova E, et al. (2006). Effects of travel distance and the season of the year on death rates of broilers transported to poultry processing plants. Poult Sci 85: 1881-1884.

Wang SX and Wu WC (2005). Effects of psychological stress on small intestinal motility and bacteria and mucosa in mice. World J Gastroenterol 11: 2016-2021.

Warriss PD (2000). Meat Science: An introductory text. CAB-International: England: Wallingford.

White HM, Richert BT, Schinckel AP, et al. (2008). Effects of temperature stress on growth performance and bacon quality in growfinish pigs housed at two densities. J Anim Sci 86: 1789-1798. 